\title{
ENCONTROS E DESENCONTROS NA DOCÊNCIA UNIVERSITÁRIA: DA ÊNFASE NO ENSINO À ÊNFASE NA APRENDIZAGEM
}

\author{
ENCUENTROS Y DESENCUENTROS EN LA DOCENCIA UNIVERSITARIA: \\ DE LA FASE DE ENSEÑANZA A LA FASE DE APRENDIZAJE
}

\section{LOST IN TRANSLATION IN UNIVERSITY TEACHING: EMPHASIS ON TEACHING THE EMPHASIS ON LEARNING}

\author{
Altair Alberto FÁ VERO ${ }^{1}$ \\ Deloíze LORENZET ${ }^{2}$
}

RESUMO: As convulsões que abalaram o mundo nos últimos tempos não poderiam deixar de afetar também a vida na universidade. A expansão da Educação Superior ocorrida nas últimas duas décadas reascende o debate de velhos e novos desafios: o que se espera da Educação Superior nesse novo cenário? Quais os motivos que impulsionaram essa expansão? Que elementos internos e externos estão atuando nesse contexto? Como está se reestruturando a Educação Superior para atender as novas demandas que estão surgindo? Como está sendo pensado o processo de ensino e de aprendizagem do grande contingente de alunos que chegam à Educação Superior? A proposta do artigo tem por escopo analisar os "encontros" e "desencontros" que emergem na docência universitária à luz das pesquisas que tem problematizado as práticas educativas nas instituições de ensino. Com o propósito de delimitar o tema de investigação, os autores optaram em analisar a docência universitária a partir de dois paradigmas: o paradigma que dá ênfase no ensino e o paradigma que dá ênfase na aprendizagem. Os autores defendem a posição de que toda e qualquer prática docente tem por trás um paradigma que precisa ser explicitado, analisado e discutido para que o processo educativo seja um ato consciente e possa sofrer intervenções que promovam sua melhoria. A não identificação do paradigma que orienta a prática docente pode resultar na ativação de atitudes alienantes que transformam a docência numa ação mecânica e instrumental. Partindo de uma contextualização dos motivos que levaram à expansão da educação superior e das consequências que tal expansão trouxe para a identidade docente, os autores realizam uma caracterização dos dois possíveis paradigmas que perpassam a docência universitária e as consequências que tal opção paradigmática possui na formação acadêmica.

PALAVRAS CHAVES: Docência universitária. Paradigma. Expansão. Políticas educacionais.

RESUMEN: Las convulsiones que han sucedido en el mundo en los últimos tiempos no pueden dejar de afectar, también, a la vida universitaria. La expansión de la Educación Superior ocurrida en las últimas dos décadas reanudan el debate de los viejos y nuevos

\footnotetext{
${ }^{1}$ Professor e pesquisador no Curso de Filosofia, no Mestrado e Doutorado em Educação da Universidade de Passo Fundo (UPF). Possui Pós-Doutorado (Bolsista Capes) pela Universidad Autónoma del Estado de México (UAEMéx). E-mail: altairfavero@gmail.com

${ }^{2}$ Mestre em Educação pelo PPGEDU. Professora do Instituto Estadual Dom Diogo de Souza, Porto Alegre/RS. E-mail: deloize@gmail.com
} 
desafíos: ¿que se espera de la Educación Superior en este nuevo escenario?, ¿cuáles son los motivos que impulsarán esta expansión?, ¿qué elementos internos, o externos, están actuando en este contexto?, ¿cómo se está la reestructurando la Educación Superior para atender las nuevas demandas que están surgiendo?, ¿cómo está siendo pensado el proceso de enseñanza y de aprendizaje en el gran contingente de alumnos que llegan a la Educación superior? La propuesta del presente artículo tiene como objeto analizar los "encuentros" y "desencuentros" que emergen en la docencia universitaria a la luz de las investigaciones que han revisado las problemáticas en las prácticas educativas en las instituciones de enseñanza. Con el propósito de delimitar el tema de investigación, los autores optaron por analizar la docencia universitaria a partir de dos paradigmas: el paradigma que da un énfasis en la enseñanza otro, el paradigma que da un énfasis en el aprendizaje. Los autores defienden la posición de que toda y cualquier práctica docente tiene escondido un paradigma que necesita ser explicado, analizado y discutido para que el proceso educativo sea un acto consciente y pueda sufrir intervenciones que promuevan su mejoría. La falta de identificación del paradigma que orienta la práctica docente puede resultar en la activación de actitudes alienantes que pueden transformar la docencia en una acción mecánica e instrumental. Partiendo de una contextualización de motivos que llevaran la expansión de la Educación Superior y de las consecuencias que tal expansión trajo para la identidad docente, los autores realizaran una caracterización de dos posibles paradigmas que sobrepasan a la docencia universitaria y las consecuencias que tal opción paradigmática posee en la formación académica.

PALABRAS CLAVE: Docencia universitária. Paradigma. Expansión. Políticas educacionales.

ABSTRACT: The convulsions that shook the world in recent times could not fail to affect college life also. The expansion of higher education took place in the past two decades reascende the debate of old and new challenges: what is expected of higher education in this new scenario? What are the grounds that boosted this expansion? Internal and external elements are acting in this context? How are you restructuring higher education to meet the new demands that are emerging? How is being thought about the teaching and learning process of the large contingent of students who come to higher education? The proposed article aims analyze the "dates" and "misunderstandings" that emerge in university teaching in the light of the research which has problematized the educational practices in educational institutions. In order to delimit the subject of research, the authors chose to examine University teaching from two paradigms: the paradigm that emphasizes education and the emphasis on learning paradigm. The authors advocate the position that any teaching practice from behind a paradigm that needs to be made explicit, analyzed and discussed so that the educational process is a conscious act and may suffer its improvement promoting interventions. Not identifying the paradigm that guides the teaching practice can result in the activation of dumbfounding attitudes that transform teaching in a mechanical action and instrumental. Starting from a contextualization of the reasons which led to the expansion of higher education and of the consequences that such expansion brought to the identity, the authors perform a characterization of two possible paradigms that pertain to university teaching and the consequences of such paradigmatic option has on academic training.

KEYWORDS: University teaching. Paradigm. Expansion. Educational policies. 


\section{Considerações Introdutórias}

No decorrer das últimas décadas a universidade e por extensão a educação superior passaram por abrangentes transformações, as quais provocaram profundas convulsões que abalaram a estrutura universitária historicamente constituída. Tais mudanças trouxeram novas configurações no cenário da educação superior $\mathrm{e}$ representam complexos desafios na identidade docente. Tais desafios passaram a fazer parte das agendas de diversos pesquisadores que nas últimas décadas se debruçaram em analisar a problemática a partir de diversas abordagens: mal-estar docente (FAVERO, 2009); indissociabilidade entre ensino, pesquisa e extensão (SAMPAIO; FREITAS, 2010); politicidade da aprendizagem (DEMO, 2010); reconstrução das práticas docentes (FREITAS; CUNHA FILHO; SOUZA; MARIZ, 2010); avaliação institucional e a formação docente (LEITE; BRAGA; FERNANDES; GENRO; FERLA, 2008); prática docente e currículos universitários (CUNHA, 2008), dentre diversos outros.

O presente trabalho tem a pretensão de pensar as seguintes problemáticas: Quais foram os fatores que provocaram as transformações na Educação Superior no Brasil? Que papel os organismos internacionais tiveram neste contexto de mudança? A expansão de instituições e de vagas ocorridas principalmente nas últimas décadas atende à demanda da democratização do acesso à Educação Superior? Com a ampliação do acesso à Educação Superior das camadas populares, de que forma é pensado o processo de ensino e aprendizagem? Esse processo pode permanecer da mesma forma de quando a Educação Superior atendia apenas à elite? Qual o paradigma que deve embasar a prática docente no processo educativo?

Deste modo, o objetivo deste artigo é compreender o processo de metamorfose vivenciado pela educação superior, identificando algumas inovações e questionando sua pertinência ou desajuste mediante a concepção de educação como direito universal. Como também, analisar os "encontros" e "desencontros" que emergem na docência universitária à luz das pesquisas que tem problematizado as práticas educativas nas instituições de ensino.

Assim, estruturalmente, este artigo é subdividido em dois momentos: o primeiro momento aborda uma contextualização da expansão da Educação Superior Brasileira e as novas considerações que passam a existir para a identidade da docência universitária; o segundo momento contempla os paradigmas do ensino e da aprendizagem, dialogando 
acerca de um paradigma que promova a emancipação ao invés de sutilmente tornar a educação um processo mecânico e instrumental.

\section{Contextualização da Expansão da Educação Superior Brasileira}

Herdamos da história da Educação Superior do Brasil inúmeras desigualdades. Esta educação chegou ao Brasil com décadas de atraso em comparação com outros países, como também sua constituição foi excludente, servindo apenas à elite. De encontro com este cenário, a partir da década de 1990 nosso país impulsionou uma vigorosa expansão. Porém, essa expansão ocorreu predominantemente na categoria privada.

As políticas públicas brasileiras têm sofrido forte influência dos preceitos dos organismos internacionais. Os receituários são divulgados por organizações como o Fundo Monetário Internacional (FMI), Banco Mundial (BM), Organização para o Desenvolvimento da Economia e do Comércio (OCDE), Organização Mundial para o Comércio (OMC), entre outras. Principalmente sendo enfáticos no que diz respeito ao acuamento Estatal e a permissividade para organizações empreendedoras privadas adentrar neste universo. Assim passam a conceber a educação superior como outro serviço comercializável qualquer e submetem aos moldes de eficiência, produtividade e competitividade assemelhando-se a oferta de outros produtos mercantilizados.

Deste modo, observamos que há mudanças desde as Instituições de Educação Superior (IES) públicas até as privadas. As IES públicas entram em crise e recebem inúmeros diagnósticos, concebidos por uma diversidade de estudiosos, adjetivações como sucateamento, precarização, desmantelamento são postos para caracterizar este tempo. Como também as IES privadas são depreciadas por priorizarem a vocação mercadológica, lucrativa, em detrimento do comprometimento com o social, com o coletivo. Nesta linha de tensão também estão as filantrópicas e comunitárias, repensando seu status e como manter a sua sobrevivência.

Esse cenário nebuloso é articulado pela necessidade de expandir o acesso da população a este nível de formação, no entanto, apesar da ampliação de instituições e de vagas ocorrida nas últimas décadas, temos segundo o último censo do Instituto Brasileiro de Pesquisas Educacionais Anísio Teixeira (INEP), um percentual baixíssimo de apenas 14,4\% da população em idade adequada, dos 18 aos 24 anos, frequentando a Educação Superior (ES) em 2009. 
Neste sentido, temos uma comprovação de que a expansão não corresponde à democratização. E apesar das características de diversificação, flexibilidade, eficiência serem permitidas legislativamente, como também, consolidando novas instituições e modalidades, ainda temos um quadro assustador de desigualdades de acesso instaurado. Observamos que com a maximização das instituições privadas crescendo desproporcionalmente, superando as públicas, atingimos uma proporção de $74,4 \%$ das matrículas em IES particulares em contrapartida com a razoável porcentagem de 25,6\% em IES públicas, segundo o censo do INEP de 2009. Deparamo-nos com um sistema fortemente manipulado pela ideia de ser algo conquistado individualmente, responsabilizado às finanças particulares, contrariando a ideia de ser um direito universal, uma causa coletiva.

Segundo a obra: “A expansão do ensino superior no Brasil: do domínio público à privatização" temos o seguinte esclarecimento de Rossato (2006, p.38):

\footnotetext{
A educação não poderia ser confiada a particulares, que somente atendem aos que tem posses, perpetuando a desigualdade social. A educação pública, comum a todos, nunca pode ser instrumento de dominação de uma camada social, mas é um direito do povo; sendo ministrada pelo Estado, deve ser obrigatória, universal e gratuita, direito do povo.
}

Assim, contrariamente a este pensamento, temos uma educação superior amplamente privada que perpetua a desigualdade social. Desta maneira, com inúmeras vagas a serem preenchidas, as IES privadas passam a ter processos seletivos menos rigorosos para facilitar a ampliação da clientela. Com isso, a partir da década de 1990 um novo nicho cultural timidamente começa a fazer parte da ES: as camadas populares. Mediante esta ideia Zabalba (2004, p.25) sinaliza: “Certamente a massificação é o fenômeno que mais se destaca na transformação da universidade e o que mais teve impacto sobre sua evolução". É louvável que haja esta conquista, porém, percebemos uma inversão no sistema, enquanto que a maioria dos alunos da Educação Básica privada vão para a ES pública, a maioria dos educandos da Educação Básica pública ingressam na ES privada. Assim, aos docentes são impostas estas mudanças, a de atender a um novo perfil de acadêmicos, que muitas vezes não dominam os conhecimentos prévios que eram exigidos antigamente.

Como também, a ideia de formação da intelectualidade perde forças, num cenário em que a demanda do mercado está assentada na prerrogativa de produzir uma mão de obra eficiente, onde o conhecimento deve ter aplicabilidade imediata. Assim, 
reconhecemos que a ES transforma suas características assemelhando-se a um mercado, onde vende o produto educativo para consumidores, determinada pela economia. Conforme Buarque (1994, p.58): "um dos principais elos da cadeia que aprisiona a universidade é o mercado". Com isso, há uma indefinição de como será a identidade do docente universitário: ao atuar com esta ideia empobrecida de formação, será reprodutor desta condição ou agente de mudança?

\section{Dialogando sobre a Docência Universitária: qual paradigma?}

É elementar lembrar que só existe docência quando há discentes e ambos se confrontam e auxiliam num processo de aprimoramento através do ensino e da aprendizagem. Ao trabalhar com a formação de outros sujeitos, buscando a construção de sua intelectualidade, deverá o docente ter o intuito de colaborar com a aquisição de conhecimentos específicos, assim como na elaboração de posturas éticas ${ }^{3}$ buscando a formação integral ou omnilateral de cada ser social, que posteriormente serão expostas em nossa sociedade, e nessa ação pedagógica ocorrerá o aperfeiçoamento de sua profissionalização, na medida em que refletirá sobre suas intervenções ${ }^{4}$. De encontro com esta ideia temos a contradição do mercado que demanda por uma formação mais produtivista, às vezes privilegiando o senso prático e empobrecendo a formação da intelectualidade.

Desta maneira, para dialogarmos acerca do tornar-se, "vir-a-ser" educador, devemos estar cientes da amplitude e profundidade que tratamos, pois, num sentido global, macroestrutural, é constituir seres humanos, em suas potencialidades, dignidade, humanidade. Nesse sentido, o docente precisa estar consciente de qual a concepção de ser humano, qual sociedade projeta, qual paradigma o orienta: do ensino ou da aprendizagem. Como nos indicam Bussmann e Abbud (2002, p.134):

É inquestionável que ensinar/aprender está na base do trabalho docente. No entanto, o ensinar e o aprender e o ensinar-aprender apresentam múltiplos significados conforme as concepções de educação, de homem e de sociedade que orientam a prática do

${ }^{3}$ Conforme Zabalza (2004, p. 39) declara "A ideia de formação pode ficar seriamente empobrecida se seu sentido se reduz à mera aquisição de uma informação nova ou ao desenvolvimento de uma nova habilidade. A importância da formação deriva, a meu ver, de sua necessária vinculação ao crescimento e ao aperfeiçoamento que tem que ser entendido em um sentido global: crescer como pessoa".

${ }^{4}$ Para Pimenta e Ghedin (2005, p.22) "O ensino como prática reflexiva tem se estabelecido como uma tendência significativa nas pesquisas em educação, apontando para a valorização dos processos de produção do saber docente a partir da prática e situando a pesquisa como um instrumento de formação de professores, em que o ensino é tomado como ponto de partida e de chegada da pesquisa". 
professor nos diferentes momentos históricos. Assim, o ensinar e o aprender, antes generalizados nas práticas sociais amplas, com o surgimento da educação escolar, adquirem contornos e conteúdos próprios que passam a caracterizar uma especificidade do trabalho do professor: ensinar/aprender.

Nesta direção, entendemos a grande responsabilidade que está incutida na função docente, na construção formativa de outros sujeitos. As finalidades por ele compreendidas como adequadas serão consideradas e seu trabalho focará alcançá-las. Aos docentes está a autonomia de decidirem sobre quais os significados que incutirão e qual o modelo de cidadãos que desejam projetar, os velhos desafios se reascendem e permanecem como novos desafios. Investigando a concepção de docência considerada a mais adequada para cada profissional podemos descobrir qual a concepção teórica que embasa sua atuação, seja ela amparada no modelo vertical, em que o docente é o portador de conhecimentos e o aluno um ser passivo a reter informações ou no modelo horizontal, em que ambos, educador e aprendiz dialogam no mesmo nível e juntos constroem, discutem os conhecimentos.

A respeito desta opção pedagógica o educador Paulo Freire, no livro Educação como prática de Liberdade enfatiza que o professor não é somente quem ensina, mas quem aprende, tornando o ensino integrado com a aprendizagem. Assim, Freire estabelecia paralelos entre as diferentes concepções de educação, como a Bancária e a Emancipatória ${ }^{5}$. Assim, o docente que tem por trás do seu processo educativo apenas o ensino estará tornando sua práxis mecânica e instrumental, a serviço da fácil dominação, enquanto que o que opta pelo paradigma da aprendizagem estará sustentando um paradigma emancipatório, centrado no processo do educando, construindo conhecimentos com criticidade.

Para melhorar o paradigma emancipatório da aprendizagem, há a necessidade de transformarmos as relações do espaço escolar da ES. O docente precisa de uma profissionalização adequada para não ser mais uma vítima deste sistema, um reprodutor de estruturas prolongadamente injustas. Assim, diz Becker (2001, p.65-66):

Como vimos, a educação precisa ser transformada não apenas no que concerne às relações de sala de aula - micromundo onde se estruturam

\footnotetext{
${ }^{5}$ A Concepção Bancária compreende o processo centrado no ensino, no professor, numa relação vertical, onde o aluno é passivo, memorizador dos saberes em busca da reprodução social. Enquanto que na Concepção Emancipatória - o processo é centrado na aprendizagem, na figura do educando como sujeito, numa relação horizontal, num processo ativo de construção de conhecimentos, na perspectiva da transformação, da luta, engajamento e comprometimento em busca da superação dos contrastes sociais, econômicos, culturais.
} 
as relações pedagógicas por excelência. Precisa ser (re)estruturada, também no que concerne à formação dos professores. Como pode um professor (re)conceber as relações pedagógicas de sala de aula se ele mesmo é vítima de uma visão precária, empirista, da matéria-prima de seu fazer - o conhecimento. Como ele pode propor e praticar a dialetização das relações entre professor e aluno, entre ensino e aprendizagem, entre saber constituído e saber constituinte, entre estrutura e função, entre ciência e acontecimentos factuais... se ele mesmo é vítima de uma visão de mundo antidialética? Como ele pode conceber o conhecimento como uma construção se sua base epistemológica é anticonstrutivista, anti-interacionista?

Neste trecho claramente são expostos alguns conceitos que o docente em sua base epistemológica, na sua constituição precisa compreender. Primeiramente, no sentido dialético, no diálogo, no movimento crítico entre sua prática e sua reflexão e fundamentação teórica. E, em segundo lugar, entendendo algumas concepções da construção, da gênese, origem do conhecimento. Assim, uma boa formação docente possibilita uma educação de melhor qualidade.

Para a constituição da docência consideramos essencial reconhecer três funções que devem ocorrer no processo educativo: 1) o conhecimento teórico dos conteúdos que nortearão as aprendizagens do educando; 2) o domínio didático, experiências pedagógicas, articuladas epistemologicamente com boas propostas de aprendizagem, desafiando, envolvendo o educando para que seja agente do processo; 3) o comprometimento com o desejo de formar cidadãos éticos, responsáveis. Deste modo, é imprescindível que para assumir a docência o profissional seja bem preparado, com formação específica em sua área de atuação, como também profundamente conhecedor da temática educação.

Da mesma forma, Cunha (2000, p.45) sinaliza um desencontro relativo à restrição da formação stricto sensu, para a formação do profissional da ES, em que a formação muitas vezes está apenas focada no princípio de ser um pesquisador, sem articulação pedagógica.

Como é amplamente conhecido entre nós, os programas de mestrado e doutorado estão organizados a partir da perspectiva da especialização em determinado recorte do conhecimento na capacitação para a pesquisa. Há um imaginário nessa perspectiva que concebe a docência como atividade científica, em que basta o domínio do conhecimento específico e o instrumental para a produção de novas informações para que se cumpram seus objetivos.

Nessa direção Cunha alerta para que a formação vá além da cientificidade de 
constituir-se um bom pesquisador, mas que esteja engajado num agir pedagógico, num processo educativo, que sua formação esteja articulada com uma práxis pedagógica.

No livro Formação de Professores: diálogo entre a teoria e a prática, Benincá e Caimi (2004, p.7), advertem sobre a necessidade de pensar a formação dos professores da seguinte maneira:

Toda e qualquer ideia sobre ensino, educação formal e vida nas escolas implica, necessariamente, um pensar sobre a formação dos profissionais que atuam neste universo: os professores. E toda e qualquer reflexão sobre a formação de professores implica, ao nosso ver, estendê-la a um tempo e a um espaço que extrapolam o tempo da graduação e o espaço da universidade; entendê-la como processo coletivo assumindo pelos próprios professores, na interação com os outros sujeitos do ato pedagógico, e aceitá-la como um desafio de superação e crescimento constantes, a despeito das dificuldades que possam advir dessa opção.

Com essa compreensão entendemos que a "titulação" não encerra-se em si mesma, pois a constituição docente será constante, acontecerá no confronto diário da interação com alunos, conhecimentos, metodologias, cumprimento de avaliações, transposição didática e realizações burocráticas de seu ofício. É exigido do docente a aprendizagem e a busca incessante pelo aprimoramento e pela profissionalização.

Falando especificamente da docência universitária e considerando o atual cenário da expansão da educação superior, cabe uma reflexão sobre a forma como é concebida a aula universitária. Tendo em vista que a expansão da Educação Superior ocorrida nas últimas duas décadas tem no ensino sua principal característica, precisamos compreender de que forma tem sido pensada a docência e de que forma ela pode ser melhorada. "Ao nos preocuparmos com a melhoria da docência”, ressalta Masetto (2005, p.80), "não podemos nos esquecer de que por trás do modo de lecionar existe um paradigma que precisa ser explicitado, analisado, discutido, a fim de que a partir dele possamos pensar em fazer alterações significativas em nossas aulas”. E quais são os paradigmas que perpassam a docência universitária? Em que sentido esses paradigmas podem representar encontros e desencontros na educação superior? Em seu texto "Docência universitária: repensando a aula", Marcos Masetto (2005) caracteriza dois possíveis paradigmas que podem perpassar a docência universitária: o paradigma do ensino e o paradigma da aprendizagem.

O paradigma do ensino, segundo Masetto (2005, p.80-81), parte do pressuposto de que o professor deve ser um transmissor de informações aos alunos e de que estes 
devem absorvê-las e reproduzi-las nos exames e provas avaliativas. Três pilares sustentam esse paradigma: 1) uma organização curricular que precisa dar conta de um número x de disciplinas; 2) um corpo docente altamente qualificado que deve "dominar com profundidade e atualização os conteúdos que deverão ser transmitidos"; 3) uma metodologia que dever "dar conta de um programa a ser cumprido, em determinado tempo, com a turma toda". O professor é o sujeito de todo o processo, pois além de ser o "centro das atividades" é também o "centro das ações": o professor é o transmissor, o comunicador, o orientador, o instrutor, aquele que mostra, aquele que avalia e dá a "última palavra". O aluno, por sua vez, é o objeto passivo que recebe, assimila, repete e devolve ao professor aquilo que foi transmitido. Mesmo que isso possa parecer exagerado, essa descrição feita por Masetto é o que com frequência acontece em muitas salas de aula.

Em sua abordagem, Masetto (2005, p.82-85) propõe substituir "a ênfase no ensino pela ênfase na aprendizagem". Não se trata de uma simples troca de palavra, mas de uma concepção na maneira como se conduz o processo pedagógico. Parte do pressuposto de que ao tratar a docência universitária na perspectiva da aprendizagem implica em compreender o aluno como um ser em desenvolvimento. A aula se torna o espaço em que os aprendizes terão a oportunidade de desenvolver suas capacidades intelectuais (pensar, raciocinar, refletir, analisar, criticar, dar significado, argumentar, produzir e socializar conhecimentos), desenvolver habilidades humanas e profissionais (saber trabalhar em equipe, conhecer fontes de pesquisa, dialogar com profissionais de outras áreas, saber expressar-se etc.) e desenvolver atitudes e valores integrantes à vida profissional (saber da importância da educação continuada, buscar soluções para problemas da profissão, ter conduta ética na condução da atividade profissional, ter responsabilidade social diante da profissão que irá exercer, etc.).

O professor na perspectiva do paradigma da aprendizagem deixa de ser o centro da transmissão do que deve ser ensinado e torna-se um mediador e orientador do processo pedagógico da aprendizagem. São redimensionados os três pilares anteriormente indicados: 1) a organização curricular passa a ser algo aberto, flexível, atualizado, interdisciplinar, integrando teoria e prática, disciplinas básicas e profissionais, formação e prática profissional; 2) o corpo docente passa a ser constituído por agentes que além de serem professores são também pesquisadores não só da sua área específica de conhecimento, mas também das competências e habilidades pedagógica, pois compreendem que a aprendizagem se realiza num processo de 
colaboração e participação dos diversos sujeitos envolvidos; 3) a metodologia é pautada pela incessante redefinição dos objetivos da aula e de seu espaço decorrente de um constante processo de avaliação e da utilização de procedimentos participativos.

O aluno deixa de ser um objeto passivo que recebe informações para se tornar um agente protagonista de aprendizagem, o que requer por parte deste a "aquisição e domínio de um conjunto de conhecimentos, métodos e técnicas científicas de forma crítica" (MASETTO, 2005, p.85). Assim, o aluno durante o processo de formação vai adquirindo uma "progressiva autonomia na aquisição de conhecimentos ulteriores" e a consciência de que é necessária uma "formação continuada" que se estende ao longo da vida. Não basta adquirir durante a formação universitária um conjunto de conhecimentos que sejam suficientes para o exercício profissional. Conforme ressalta o relatório Delors (1999, p.89) “é, antes, necessário estar à altura de aproveitar e explorar, do começo ao fim da vida, todas as ocasiões de atualizar, aprofundar e enriquecer estes primeiros conhecimentos, e de se adaptar a um mundo em mudança".

A Comissão Internacional que elaborou o Relatório para a Unesco sobre a Educação do século XXI, foi incisiva ao dizer que "para poder dar resposta ao conjunto de suas missões, a educação deve organizar-se em torno de quatro aprendizagens fundamentais que, ao longo de toda a vida, serão de algum modo para cada indivíduo, os pilares do conhecimento" (DELORS, 1999, p.89-90). Os quatro pilares indicados pela comissão são os seguintes: aprender a conhecer, aprender a fazer, aprender a viver juntos e aprender a ser. O próprio relatório ressalta que "o ensino formal", em regra geral, orienta-se quase que exclusivamente para o aprender a conhecer e em menor escala para o aprender a fazer, marginalizando as outras duas aprendizagens. Isso corrobora a tese de que ainda estamos fatalmente contaminados pelo paradigma do ensino. A Comissão enfatiza que “cada um dos ‘quatro pilares do conhecimento' deve ser objeto de atenção igual por parte do ensino estruturado, a fim de que a educação apareça como uma experiência global” (DELORS, 1999, p.90). Dificilmente a Educação Superior conseguirá dar conta de sua missão formativa na perspectiva dos "quatro pilares" caso continuar a estruturar-se no paradigma do ensino. Dificilmente teremos profissionais conscientes da dimensão social da própria profissão ou mesmo da necessidade da formação continuada se durante seu processo formativo formal foram tratados como receptáculos de depósito de informações. O prazer de compreender, de conhecer, de descobrir, de inovar, somente se efetiva se o próprio processo formativo oportunizar tais práticas. Por isso a aula universitária deverá ser um tempo e um espaço 
que "favorece o despertar da curiosidade intelectual, estimula o sentido crítico e permite compreender o real, mediante a aquisição de autonomia na capacidade de discernir" (DELORS, 1999, p.91).

Conforme já referimos acima, não se trata de uma simples troca de palavras ou de uma troca de técnicas pedagógicas, mas sim de uma mudança de concepção. Mudase a pergunta que mobiliza a prática docente: se no paradigma do ensino a pergunta que mobiliza o professor é "o que devo ensinar aos meus alunos?", no paradigma da aprendizagem o pergunta que orienta o trabalho docente é "o que meu aluno precisa aprender de todo o conhecimento que tenho e de toda a experiência que tenho vivido para que ele possa desenvolver sua formação profissional?". Percebe-se que há uma profunda mudança de ângulo, pois ocorre um reordenamento do processo educativo. De nada adianta o professor ensinar se os alunos não aprendem; de nada adianta repassar informações se estas não passarem a fazer parte do "horizonte de sentido" dos aprendizes. Que consequências a mudança da ênfase no ensino para a ênfase na aprendizagem pode ter no atual cenário da educação superior? No nosso entendimento, dentre as consequências, pode haver uma instigante alteração na qualidade educativa.

\section{Considerações finais}

Como avistamos anteriormente, o educador pode eleger entre duas possibilidades para exercer a sua docência, em qualquer âmbito, inclusive na docência universitária. São eles: o processo centrado no ensino ou o processo centrado na aprendizagem.

Possivelmente o educador que sustenta sua práxis pedagógica no paradigma do ensino estará sendo conivente à reprodução deste modelo de sociedade desigual, em que os direitos básicos de educação, saúde, moradia, saneamento não são assegurados a todos os cidadãos. E assim manterá as injustiças sociais perante as minorias étnicas culturais, auxiliando a ampliação dos polos econômicos entre poucos abastados e muitos pobres e miseráveis.

Nesta direção, o educando estará suficientemente adequado para realizar os procedimentos técnicos que foram ensinados, porém, não foi preparado para pensar sobre seu trabalho, sobre as condições da convivência em sociedade e todo o processo de exploração que geralmente tem por trás do processo produtivo. Como também, não podemos esperar desse modelo educativo posições críticas e criativas sobre a ciência, a 
sociedade, o conhecimento, a política, o meio ambiente e a própria profissão, pois o mesmo é mero reprodutor, copiador fidedignamente de uma identidade previamente estabelecida. A autonomia é visivelmente substituída pela formatação de um profissional robotizado que apenas executa procedimentos programados num determinado contexto.

A ênfase no paradigma da aprendizagem parte do pressuposto de que todo conhecimento que perpassa o processo formativo precisa ser significativo para o aprendiz. Uma das grandes tarefas da universidade, como também da Educação Superior nesse contexto é tornar o processo formativo um espaço de educação do olhar a fim de desenvolver nos aprendizes a capacidade de perceber os fenômenos problemáticos que encontram no exercício de sua profissão, bem como desenvolver a capacidade de compreender a complexidade do mundo social em que vivemos. Como ressaltam Pimenta e Anastasiou (2008, p.173):

\begin{abstract}
A universidade não deve simplesmente adequar-se às oscilações do mercado, mas aprender a olhar em seu entorno, a compreender e assimilar os fenômenos, a produzir respostas às mudanças sociais, a preparar globalmente os estudantes para as complexidades que se avizinham, a situar-se como instituição líder, produtora de ideias, culturas, artes e técnicas renovadas que se comprometam com a humanidade, com o processo de humanização.
\end{abstract}

Nada mais oportuno para o nosso tempo. A renovação e a sobrevivência da universidade dependem em grande parte da capacidade de enfrentar esses desafios que perpassam seu cotidiano nas diversas formas de relacionamento. Tais respostas não são exteriorizações e exclusivamente resultado de mecanismos formais e burocráticos, mas acima de tudo atitudes e comportamentos dos diversos sujeitos que nela atuam.

\title{
REFERÊNCIAS
}

ABBUD, Maria Luiza Macedo; BUSSMANN, Antônia Carvalho. Trabalho docente. In: BRZENSKI, Iria. (Org.). Profissão professor: identidade e profissionalização docente. Brasília: Plano Editora, 2002.

BECKER, Fernando. Educação e Construção do Conhecimento. Porto Alegre: Artmed Editora, 2001.

BENINCÁ, Elli; CAIMI, Flavia Eloisa. (Org.). Formação de Professores: diálogo 
entre a teoria e a prática. 2. ed. Passo Fundo: UPF, 2004.

BRASIL, Ministério da Educação e da Cultura. Instituto Nacional de Estudos e Pesquisas Educacionais Anísio Teixeira (INEP). Resumo Técnico do Censo da Educação Superior 2009. Disponível em:

$<$ http://www.inep.gov.br/superior/censosuperior/relatorio_tecnico.htm $>$. Acesso em 24 jun. 2011.

BUARQUE, Cristovam. A Aventura da Universidade. São Paulo: Editora da Universidade Estadual Paulista; Rio de Janeiro: Paz e Terra, 1994.

CUNHA, Maria Isabel da. Aportes teóricos e reflexões da prática: a emergente reconfiguração dos currículos universitários. In: MASETTO, Marcos (org.). Docência na universidade. 9 ed. Campinas/SP: Papirus, 2008, p.27-38.

CUNHA, Maria Isabel da. Ensino como mediação da formação do professor universitário. IN: MOROSINI, Marília Costa. (Org.). Professor do Ensino Superior: identidade, docência e formação. Brasília: Instituto Nacional de Estudos e Pesquisas Educacionais, 2000.

DELORS, Jacques (org.). Educação: um tesouro a descobrir. 2 ed. São Paulo: Cortez, 1999.

DEMO, Pedro. Politicidade da aprendizagem. In: FREITAS, Lêda Gonçalves; MARIZ, Ricardo Spindola; CUNHA FILHO, José Leão (orgs.). Educação superior: princípios, finalidades e formação continuada de professores. Brasília: Liber Livro; Universa, 2010.

FÁVERO, Altair Alberto. Políticas de formação pedagógica: possibilidades de superar o mal-estar docente. IN: CENCI, Ângelo Vitório; DALBOSCO, Claudio Almir; MÜHL, Eldon Henrique. (Org.). Sobre Filosofia e Educação: racionalidade, diversidade e formação pedagógica. Passo Fundo: Editora UPF, 2009, p.403-419.

FREIRE, Paulo Neves. Educação como Prática de Liberdade. Rio de Janeiro: Paz e Terra, 1989.

FREITAS, Lêda Gonçalves; MARIZ, Ricardo Spindola; SOUZA, Carlos Alberto Lopes de; CUNHA FILHO, José Leão In: Reconstrução das práticas docentes: uma estratégia para a formação de professores a partir da prática. In: FREITAS, Lêda Gonçalves; MARIZ, Ricardo Spindola; CUNHA FILHO, José Leão (orgs.). Educação superior: princípios, finalidades e formação continuada de professores. Brasília: Liber Livro; Universa, 2010.

LEITE, Denise; BRAGA, Ana Maria; FERNANDES, Cleoni; GENRO, Maria Elly; FERLA, Alcindo. A avaliação institucional e os desafios da formação docente na universidade pós-moderna. In: MASETTO, Marcos (org.). Docência na universidade. 9 ed. Campinas/SP: Papirus, 2008.

MASETTO, Marcos. Docência universitária: repensando a aula. In: TEODORO, Antonio; VASCONCELLOS, Maria Lúcia (orgs.). Ensinar e aprender no ensino superior: por uma epistemologia da curiosidade na formação universitária. 2 ed. São Paulo: Mackenzie; Cortez, 2005. 
PIMENTA, Selma Garrido; ANASTASIOU, Léa das Graças Camargo. Docência no Ensino Superior. São Paulo: Cortez, 2008.

PIMENTA, Selma Garrido; GHEDIN, Evandro. (Org). Professor Reflexivo no Brasil: gênese e crítica de um conceito. São Paulo: Cortez, 2005.

QUADROS, Claudemir de. (Org.). Trabalho docente na educação superior: proposições e perspectivas. Santa Maria: Centro Universitário Franciscano, 2003.

ROSSATO, Ermelio. A expansão do ensino superior no Brasil: do domínio público à privatização. Passo Fundo: Ed. da Universidade de Passo Fundo, 2006.

SAMPAIO, Jorge Hamilton; FREITAS, Marta Helena. A indissociabilidade entre ensino, pesquisa e extensão. In: FREITAS, Lêda Gonçalves; MARIZ, Ricardo Spindola; CUNHA FILHO, José Leão (orgs.). Educação superior: princípios, finalidades e formação continuada de professores. Brasília: Liber Livro; Universa, 2010.

ZABALZA, Miguel A. O ensino universitário: seu cenário e seus protagonistas. Tradução de Ernani Rosa. Porto Alegre: Artmed, 2004.

\section{Como referenciar este artigo}

FÁVERO, Altair Alberto.; LORENZET, Deloíze. Encontros e Desencontros na Docência Universitária: da ênfase no ensino à ênfase na aprendizagem. Revista IberoAmericana de Estudos em Educação, Araraquara, v. 11, n. 4, p. 1849-1863, 2016. Disponível em: <http://dx.doi.org/10.21723/riaee.v11.n4.6344>. E-ISSN: 1982-5587.

Submetido em: setembro/2013

Aprovação final em: julho/2016 